\title{
Bioanalysis
}

\section{Analysis of aluminium in rat following administration of allergen immunotherapy using either aluminium or microcrystalline-tyrosine-based adjuvants}

\begin{abstract}
Background: Investigation into the absorption, distribution and elimination of aluminium in rat after subcutaneous aluminium adjuvant formulation administration using ICP-MS is described. Method \& results: Assays were verified under the principles of a tiered approach. There was no evidence of systemic exposure of aluminium, in brain or in kidney. Extensive and persistent retention of aluminium at the dose site was observed for at least 180 days after administration. Conclusion: This is the first published work that has quantified aluminium adjuvant retention based on the quantity of aluminium delivered in a typical allergy immunotherapy course. The results indicate that the repeated administration of aluminium-containing adjuvants will likely contribute directly and significantly to an individual's body burden of aluminium.
\end{abstract}

First draft submitted: 21 October 2015; Accepted for publication: 12 January 2016; Published online: 26 February 2016

Keywords: adjuvant $\bullet$ ADME $\bullet$ body burden $\bullet$ ICP-MS $\bullet$ ICP-MS sample digestion $\bullet$ SCIT - subcutaneous $\bullet$ tiered approach $\bullet$ tissue distribution

Subcutaneous immunotherapy (SCIT) is a highly effective treatment for IgE-mediated allergic diseases, including venom anaphylaxis and seasonal rhinoconjunctivitis, and provides treatment for allergy by helping to rebalance an individual's immune response to allergens. Immunotherapy is commonly administered by subcutaneous injection of natural or modified allergen extracts. Allergen immunotherapy is typically performed over a long duration and a patient can, in some instances, receive more than 70 injections over a 5-year period [1]. Immunotherapy vaccines are often delivered in gradually increasing doses during an up-dosing phase until a maintenance dose is reached. The ability to drive an antibody titre response is greatly improved by the use of adjuvants, the most common being aluminium hydroxide. However, persistent granuloma formation has been associated with this adjuvant [2] and it has been suggested that aluminium has a propensity to accumulate in tissues [1].
Currently, regulatory authorities set aluminium limits per dose, rather than per treatment course. A maximum dose of $1.25 \mathrm{mg}$ $\mathrm{Al}^{3+}$ in a single vaccine shot is permitted by the US Code of Federal Regulations, which is aligned with the WHO and European standards per single human dose of a product [3-5]. The limits were empirically selected from safety data, adjuvanticity, and the risk/benefit ratio. However, the current risk/benefit risk assessment in the use of aluminium in longercourse therapy has been challenged, since the regulatory limits are set per dose and not per treatment course [1].

No preclinical models on the localization kinetics of aluminium after subcutaneous injection, based on allergy formulations currently exist. The objective of this study was to investigate the absorption, distribution and elimination of aluminium in rat by inductively coupled plasma MS (ICP-MS), based on a typical human 3-year subcutaneous
Stuart A McDougall*,1, Matthew D Heath ${ }^{2}$, Matthias $\mathrm{F} \mathrm{Kramer}^{3}$ \& Murray A Skinner $^{2}$

${ }^{1}$ ARCINOVA, Willowburn Avenue,

Alnwick, Northumberland, NE66 2JH, UK ${ }^{2}$ Allergy Therapeutics plc, Dominion Way, Worthing, BN14 8SA, UK ${ }^{3}$ Bencard Allergie $\mathrm{GmbH}$, Messerschmittstr. 4, 80992 München, Germany

*Author for correspondence:

Tel.: +44 1665608405

Fax +44 1665608327

stuart.mcdougall@arcinova.uk

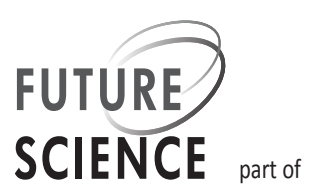


immunotherapy dose regimen adjusted by bodyweight scaling.

\section{Experimental}

\section{Standards \& chemicals}

High purity (>99.999\%) argon gas (BOC Gases, UK) was used for ICP-MS analysis. ASTM Type I ultrapure water $(>18 \mathrm{M} \Omega)$ was provided in-house by an Elga Purelab-Ultra system (Veolia Water Technologies, UK). Aluminium and Scandium (internal standard) Specpure ${ }^{\circledR}$ ICP-MS grade standard reference solutions were obtained from Alfa Aesar. Electronic grade (25\% w/w) tetramethylammonium hydroxide (TMAH) was obtained from Alpha Aesar, USA. Ethylenediaminetetraacetic acid (ACS Grade), ammonium chloride (Trace Metal grade), phosphate-buffered saline (PBS) and nitric acid (electronic grade) were obtained from Sigma-Aldrich, UK. Solvable ${ }^{\mathrm{TM}}$ was obtained from Perkin Elmer, UK. Alhydrogel ${ }^{\circledR}$ 2\% aluminium hydroxide gel (Brenntang Nordic A/S) was obtained from InvivoGen, USA. A preparation of $2 \%$ Tyrosine solution formulated for optimized depot adjuvancy known as Micro-Crystalline-Tyrosine (MCT), birch allergen extract concentrate and buffered saline solution $(\mathrm{pH}$ 6.0 with $0.5 \%$ Phenol) was supplied by Allergy Therapeutics, UK. The birch allergen extract concentrate was chosen as the representative allergenic material and the $2 \%$ Alhydrogel (9-11 $\mathrm{mg} \mathrm{Al}{ }^{3+} / \mathrm{ml}$ ) and $2 \%$ tyrosine (MCT) solution as the depot adjuvants.

\section{Dose formulation}

The aluminium formulation was prepared by mixing buffered saline ( $\mathrm{pH} \mathrm{6)}$, birch allergen extract concentrate and Alhydrogel 2\% aluminium hydroxide gel, while the MCT formulation (aluminium-free adjuvant comparator) was prepared by mixing buffered saline, birch allergen extract concentrate and tyrosine solution $(2 \%)$. The control dose formulation was buffered saline solution. Samples of the prepared aluminium formulation were analyzed for aluminium content by a validated ICP-MS assay characterized for linearity of response, repeatability of injection, sensitivity and accuracy. Replicate aliquots $(n=3)$ of the aluminium formulation were sampled (top, middle and bottom of vial) on the day of preparation and demonstrated that the formulation was homogenous for aluminium content. In addition, replicate aliquots $(\mathrm{n}=3)$ were sampled after 3 days' storage at ambient temperature and demonstrated that the formulation was stable for aluminium content when prepared as described.

\section{Animals}

Fifty-one male Han Wistar rats were obtained from Charles River, UK Limited and acclimatized prior to dosing. During this time the health status of the animals and their suitability for experimental purposes was confirmed. The animals were housed up to five per cage in solid floor cages containing suitable bedding. They were kept in rooms thermostatically maintained at a temperature of $19-24^{\circ} \mathrm{C}$, with a relative humidity of between 37 and $67 \%$, and exposed to fluorescent light (nominal $12 \mathrm{~h}$ ) each day. Temperature and relative humidity were recorded on a daily basis. The facility was designed to give 15-20 air-changes/h. In order to enrich both the environment and the welfare of the animals, they were provided with wooden Aspen chew blocks and polycarbonate tunnels. In order to reduce the potential for contamination and further reingestion of drug-related material, the bedding, chew blocks and tunnels were replaced on the afternoon after dosing and again on the following day. All animals were allowed free access to commercial pellet diet, SQC Rat and Mouse Maintenance Diet No 1 (Special Diets Services, UK) and free access to mains water from bottles attached to the cages. Bodyweights were recorded the day after arrival and before dose administration (nominal $220 \pm 40 \mathrm{~g}$ ).

Each animal received a single subcutaneous administration on four occasions with a 3 or 4 day interval between administrations. Doses were administered into the subcutis at the nape of the neck at a nominal dose volume of $0.4 \mathrm{ml} /$ animal. A summary of the dosing is presented in Table 1. Final aluminium and tyrosine concentrations (per dose) were calculated using human/rat weight conversions to reflect a typical 3-year immunotherapy treatment in man.

Triplicate animals from aluminium formulation and MCT formulation-treated groups were humanely sacrificed at 1, 3, 7, 14, 30, 45, 90 and 180 days after the final dose administration. The three control animals were sacrificed $24 \mathrm{~h}$ after the last administration of control vehicle.

Animals were killed by intraperitoneal barbiturate overdose followed by cervical dislocation and severance of the major blood vessels of the neck. At sacrifice, a terminal blood sample (up to $2 \mathrm{ml}$ ) was collected from each animal into tubes containing lithium heparin anticoagulant and kept at room temperature. Half of the sample was removed and retained as whole blood while the remainder was processed to prepare plasma. Following centrifugation, remaining blood cells were discarded and the plasma transferred to polypropylene tubes. Blood and plasma was retained and stored frozen at a temperature of less than $-50^{\circ} \mathrm{C}$ prior to ICP-MS analysis. Brain, bone, muscle, liver, lung and kidney were harvested by dissection and stored frozen at a temperature of less than $-50^{\circ} \mathrm{C}$ prior to analysis, together with the remaining animal carcasses. 
Table 1. Subcutaneous administration of aluminium, microcrystalline tyrosine and control

formulations to male rats.

\begin{tabular}{|c|c|c|c|c|}
\hline \multirow[t]{2}{*}{ Dose route } & \multirow[t]{2}{*}{ Test substance } & \multicolumn{2}{|c|}{ Administered dose (adjuvant) } & \multirow{2}{*}{$\begin{array}{l}\text { Number of } \\
\text { animals }\end{array}$} \\
\hline & & $\mathrm{mg} / \mathrm{dose}^{\dagger}$ & $\mathbf{m g} / \mathbf{k g}^{\ddagger}$ & \\
\hline Subcutaneous & Aluminium formulation & 0.043 & 0.69 & 24 \\
\hline Subcutaneous & MCT formulation & 0.240 & 3.83 & 24 \\
\hline Subcutaneous & Control vehicle & 0 & 0 & 3 \\
\hline
\end{tabular}

During the course of the study, no overt pharmacological or toxicological signs that could have been attributed to the administration of Aluminium or MCT formulations were observed in the test animals.

\section{ICP-MS analysis of aluminium}

All analysis was performed in a dedicated ACDP (UK Advisory Committee on Dangerous Pathogens) Class II bio-facility and all sample processing and digestion was performed inside Class I HEPA filtered biosafety cabinets to minimize the risks of contamination. All elemental reference standard preparation ( $\mathrm{Al}$ and $\mathrm{Sc}$ ) was performed in a separate and dedicated laboratory to further eliminate the potential for sample contamination. All solutions, reference standards, sample collection, processing, digestion and analysis processes were performed in polypropylene labware to remove any potential for aluminium background interference arising from laboratory borosilicate glassware.

Aluminium at $\mathrm{m} / \mathrm{z} 27$ and scandium at $\mathrm{m} / \mathrm{z} 45$ were measured using an Agilent 7700x ICP-MS instrument (Agilent Technologies UK Ltd) equipped with a Cetac ASX520 autosampler, ISIS (Intelligent Sample Introduction System), Octopole Reaction System $\left(\mathrm{ORS}^{3}\right)$, nickel sampling and skimmer cones and MicroMist quart nebulizer set at $2^{\circ} \mathrm{C}$. The ICP-MS was operated at $1550 \mathrm{~W}$ in Helium cell gas mode (at $4.31 / \mathrm{min}$ ) to reduce polyatomic interferences. The system was controlled using Agilent MassHunter (version B.01) software. The integration time was 0.3 seconds/point, one point per mass and three replicates per analysis. All regression and quantitation was performed using Watson LIMS version 7.4.1 (Thermo Fisher Scientific, USA).

\section{Blood \& plasma}

An investigative ICP-MS method for quantification of aluminium in rat lithium heparin blood and plasma was developed. In summary, an aliquot $(0.1 \mathrm{ml})$ of sample was mixed with $4.9 \mathrm{ml}$ of $1 \%$ TMAH/1\% EDTA containing Scandium internal standard and digested in polypropylene tubes at ambient tempera- ture before being analyzed for aluminium content by ICP-MS. Calibration samples were prepared in PBS at concentrations of 10,25, 50,100,250, 500, 1000 and $2500 \mathrm{ng} / \mathrm{ml}$ and analyzed in duplicate. QC samples were matrix matched and prepared in rat plasma and blood at final aluminium concentrations of 25,250 and $2000 \mathrm{ng} / \mathrm{ml}$.

\section{Kidney \& brain}

Investigative ICP-MS methods for quantification of aluminium in rat kidney and brain were developed. In summary, rat kidney or brain was homogenized in two volumes of PBS using an Ultra-Turrax homogeniser (IKA Werke GmbH, Germany). An aliquot $(0.1 \mathrm{~g})$ of sample was mixed with $350 \mu \mathrm{l}$ of PE Solvable ${ }^{\mathrm{TM}}$, rotary mixed, incubated for $15 \mathrm{~min}$ at approximately $50^{\circ} \mathrm{C}$, rotary mixed again and then diluted with $4.9 \mathrm{ml}$ of $1 \%$ TMAH/1\% EDTA containing Scandium internal standard. The sample was then further digested for 1 $h$ at ambient temperature before being analyzed for aluminium content by ICP-MS.

Calibration samples were prepared in PBS at concentrations of 10,25, 50,100,250,500, 1000 and $2500 \mathrm{ng} / \mathrm{g}$ and analyzed in duplicate. Quality control samples were matrix matched and prepared in rat kidney or rat brain homogenate at final aluminium concentrations of 25,250 and $2000 \mathrm{ng} / \mathrm{g}$.

\section{Subcutaneous dose site}

An investigative ICP-MS method for quantification of aluminium in subcutaneous dose site was developed. In summary, the excised subcutaneous (sc.) dose sites were digested in polypropylene tubes for at least $4 \mathrm{~h}$ at $60^{\circ} \mathrm{C}$ in 3 volumes of $70 \%$ electronic grade nitric acid. An aliquot $(30 \mu \mathrm{l})$ of each digest was diluted with $20 \mu \mathrm{l}$ of $2 \%$ nitric acid and then mixed and further digested with $1.9 \mathrm{ml}$ of $2 \%$ nitric acid containing the Scandium internal standard. Samples were then analyzed for aluminium content by ICP-MS.

Calibration samples were prepared in $2 \%$ nitric acid at concentrations of 10,25, 50, 100, 250, 500, 1000 and $2500 \mathrm{ng} / \mathrm{ml}$ and analyzed in duplicate. Quality control 
samples were prepared in rat liver homogenate at final aluminium concentrations of 25, 250 and $2000 \mathrm{ng} / \mathrm{g}$. The rat liver homogenate was chosen as a surrogate of subcutaneous tissue since control tissue to prepare direct matrix-matched QC samples was not available.

\section{Statistical analysis}

Bias or percent bias (\%Bias), a term commonly used in bioanalysis to describe the accuracy of the measure versus the known or theoretical concentration, was calculated as ([measured concentration - known concentration $] /$ known concentration) $\times 100$. The relative standard deviation (RSD\%), used to describe the precision of the measurement, was calculated from the standard deviation of the measurement results divided by the mean of the measurement results and expressed as a percentage.

\section{Results \& discussion}

During development of the ICP-MS assay for aluminium in plasma, but prior to entering the formal regulatory compliant assay validation phase [6,7], selected study samples were assayed to ensure that the final assay would have the required sensitivity and dynamic range to support the needs to the project. Unexpectedly, all results obtained during that initial assessment were below the LLOQ $(10 \mathrm{ng} / \mathrm{ml})$ and it was decided not to continue with the series of regulatory assay validations (plasma, blood, tissue) but to proceed with fit for purpose investigative assays, in line with the concepts of a 'tiered approach' to bioanalysis [8-12]. While the precision and accuracy of each assay was not fully characterized, especially at the LLOQ, these 'fit for purpose' research assays were sufficient to investigate aluminium exposure in biological fluids and tissues and locate the administered aluminium dose.

The investigative assay for aluminium was verified with replicate $(\mathrm{n}=6)$ QC rat plasma samples at 25, 250 and $2000 \mathrm{ng} / \mathrm{ml}$ (Table 2) versus a linear calibration curve (weighting 1/concentration) over a dynamic range of 10 to $2500 \mathrm{ng} / \mathrm{ml}$ in PBS. Study samples collected at 1,14 and 45 days after sc. administration of the aluminium formulation were analyzed and all results were less than LLOQ $(10 \mathrm{ng} / \mathrm{ml})$. In view of these plasma results, selected rat blood samples collected at 1 , 14 and 45 days after sc. administration of the aluminium formulation and at 1 day after administration of the MCT formulation were analyzed using the investigative assay for aluminium in rat blood. Once again, a linear calibration curve (weighting $1 /$ concentration) over a dynamic range of 10 to $2500 \mathrm{ng} / \mathrm{ml}$ in PBS was used. Quality control blood samples ( $n=2$ per level) at 25,250 and $2000 \mathrm{ng} / \mathrm{ml}$ were analyzed with the study samples and had bias versus nominal of $-18.4,-1.2$ and $-3.5 \%$, respectively. All blood samples had aluminium concentrations of less than LLOQ (10 $\mathrm{ng} / \mathrm{ml})$.

However, 'absence of evidence is not evidence of absence' [13]. Aluminium is one of the most challenging elements to detect and quantify at trace levels by ICP-MS, with LLOQs similar to our assay reported elsewhere [14,15]. As such, with no apparent systemic exposure of aluminium which may have been a result of the concentrations being below our limit of detection for aluminium by ICP-MS, the investigation

\begin{tabular}{|lllllllllll|}
\hline \multirow{2}{*}{ Table 2. Verification of investigative assays for aluminium in rat plasma, kidney and brain. } \\
& \multicolumn{7}{c}{ Matrix } \\
\cline { 2 - 11 } & Plasma & \multicolumn{7}{c|}{ Kidney } & \multicolumn{3}{c|}{ Brain } \\
Theoretical concentration $(\mathrm{ng} / \mathrm{ml})$ & 25.0 & 250 & 2000 & 25.0 & 250 & 2000 & 25.0 & 250 & 2000 \\
\hline Found conc. $(\mathrm{ng} / \mathrm{ml})$ & & & & & & & & & \\
\hline$\# 1$ & 20.0 & 258 & 1930 & $342^{+}$ & 340 & 2410 & 16.3 & 221 & 1890 \\
$\# 2$ & 24.4 & 259 & 1950 & 119 & 349 & 2400 & 15.9 & 236 & 2120 \\
$\# 3$ & 23.7 & 256 & 2180 & 103 & 363 & 2460 & 20.5 & 227 & 2140 \\
$\# 4$ & 19.8 & 244 & 2080 & 60.8 & 269 & 2320 & 10.7 & 227 & 1950 \\
$\# 5$ & 28.3 & 237 & 1910 & 141 & 310 & 2370 & 14.5 & 244 & 2150 \\
$\# 6$ & 27.0 & 269 & 2120 & 93.5 & 316 & 2330 & 13.4 & 240 & 2160 \\
\hline Mean & 23.9 & 254 & 2030 & 103 & 325 & 2380 & 15.2 & 233 & 2070 \\
\hline Standard deviation & 3.50 & 11.5 & 113 & 29.9 & 33.7 & 52.7 & 3.28 & 8.87 & 117 \\
\hline RSD (\%) & 14.6 & 4.5 & 5.6 & 28.9 & 10.4 & 2.2 & 21.6 & 3.8 & 5.7 \\
\hline \%Bias & -4.4 & 1.6 & 1.5 & 314 & 30.0 & 19.0 & -39.2 & -6.8 & 3.5 \\
\hline n & 6 & 6 & 6 & 5 & 6 & 6 & 6 & 6 & 6 \\
\hline +Outlier excluded from statistical calculations & & & & & & & & \\
\hline
\end{tabular}


Table 3. Calibration data for aluminium (in $2 \%$ nitric acid) used for subcutaneous dose site analysis.

\begin{tabular}{|c|c|c|c|c|c|c|c|c|}
\hline Concentration $(\mathrm{ng} / \mathrm{ml})$ & 10.0 & 25.0 & 50.0 & 100 & 250 & 500 & 1000 & 2500 \\
\hline \multirow[t]{2}{*}{ Run 1} & $24.6^{+}$ & 31.3 & 43.3 & 79.6 & $183^{+}$ & 562 & 988 & 2480 \\
\hline & $41.4^{+}$ & 33.1 & $110^{+}$ & 84.2 & 190 & $353^{+}$ & 1060 & 2500 \\
\hline \multirow[t]{2}{*}{ Run 2} & $25.0^{\dagger}$ & 25.4 & 41.9 & 97.5 & 252 & 483 & 986 & 2450 \\
\hline & 12.0 & $36.8^{+}$ & 53.9 & 89.3 & 228 & 522 & 1120 & 2470 \\
\hline Mean & 12.0 & 29.9 & 46.4 & 87.7 & 223 & 522 & 1040 & 2480 \\
\hline Standard deviation & NC & 4.03 & 6.56 & 7.67 & 31.3 & 39.5 & 64.3 & 20.8 \\
\hline RSD (\%) & NC & 13.5 & 14.1 & 8.7 & 14.0 & 7.6 & 6.2 & 0.8 \\
\hline$\%$ Bias & 20.0 & 19.6 & -7.2 & -12.3 & -10.8 & 4.4 & 4.0 & -0.8 \\
\hline $\mathrm{n}$ & 1 & 3 & 3 & 4 & 3 & 3 & 4 & 4 \\
\hline
\end{tabular}

focused on whether any so far undetectable systemic aluminium had accumulated in rat kidney, the major organ for aluminium elimination [16] or in rat brain.

The investigative assays for aluminium in rat kidney and brain homogenate were both verified (Table 2). Calibration was performed over a dynamic range of 10 to $2500 \mathrm{ng} / \mathrm{ml}$ in PBS (linear 1/concentration weighting). Rat kidney QC homogenate samples ( $n=6 /$ level) at 25,250 and $2000 \mathrm{ng} / \mathrm{ml}$ had bias versus nominal of $314,30.0$ and $19.0 \%$, whereas the rat brain QC homogenate samples $(\mathrm{n}=6 / \mathrm{level}$ at 25,250 and $2000 \mathrm{ng} / \mathrm{ml}$ ) had bias versus nominal of $-39.2,-6.8$ and $3.5 \%$, respectively.

For kidney, analysis of study samples collected 1 day after sc. administration of aluminium or tyrosine adjuvant formulations could not detect aluminium. Similarly, rat brain samples collected 90 days after dosing could also not detect aluminium. However, it was noted that the kidney and brain tissue assays that used Solvable ${ }^{\mathrm{TM}}$ to digest the solid material were more variable and higher limits of quantification of 50 and $25 \mathrm{ng} / \mathrm{g}$ were achieved, respectively. Although, considering that aluminium was still undetectable in study samples, the performance of these investigative ICPMS methods were sufficient for the purposes of this study.

At this point, with no evidence of systemic circulation or distribution and accumulation of aluminium into tissues, or assays with an insufficient limit of detection for aluminium, it was decided to excise the sc. dose sites from the stored and frozen animal carcasses. The Alhydrogel adjuvant is an aluminium hydroxide wet gel suspension which has a particle size distribution $(\sim 2-10 \mu \mathrm{m})$ comparable to the size of microorganisms and is adequate for uptake by phagocytosis by antigen presenting cells $[17,18]$. In addition, aluminium hydroxide has a very low solubility at physiological $\mathrm{pH}[19]$ and as such, the aluminium adjuvant may well have become localized at the sc. dose sites. Whilst not an impossible task, the sc. dosing on four separate occasions into the nape of the neck meant that accurate excision of the whole dose site without any visual indicator was physically difficult. The dose sites were excised on two separate occasions; those from aluminium and MCT treated animals at 1 day after dosing were excised first and then those from aluminium treated animals at 7, 14 and 180 days after dosing later. The average mass excised differed between the two groups, with the day 1 samples averaging $7.4 \mathrm{~g}$, while the day 7,14 and 180 day samples were over twice as large (average $17.5 \mathrm{~g}$ ).

The sc. dose site samples were analyzed together with rat liver homogenate $\mathrm{QC}$ samples $(\mathrm{n}=2$ per level) at 25,250 and $2500 \mathrm{ng} / \mathrm{ml}$ and a calibration curve (linear with weighting $1 /$ concentration) over a dynamic range of $10-2500 \mathrm{ng} / \mathrm{ml}$ in $2 \%$ nitric acid on two separate occasions. Rat liver homogenate was used as a surrogate matrix for the sc. dose site. The process of hot incubation of the samples in concentrated nitric acid ensured complete digestion and proved more reliable than using Solvable ${ }^{\mathrm{TM}}$. The mean bias for the QC samples were $25.2,-30.4$ and $-18.8 \%$ at 25,250 and 2500 $\mathrm{ng} / \mathrm{ml}$, respectively. The calibration data are presented in Table 3 and demonstrated acceptable accuracy and precision between 25 and $2500 \mathrm{ng} / \mathrm{ml}$.

Significant aluminium concentrations were found in the sc. dose sites of aluminium treated animals and absent in both the MCT and control groups. The aluminium concentrations detected by ICP-MS were corrected for dilution to calculate the total mass of aluminium associated with the dose site $(\mu \mathrm{g})$ and then based on the known mass of aluminium administered to each animal, calculated the percent administered dose associated with that dose site (Table 4).

It was concluded that there was extensive and persistent retention of aluminium at the subcutaneous dose 
Table 4. Concentration, mass and percent aluminium dose associated with subcutaneous dose sites.

\begin{tabular}{|c|c|c|c|c|c|c|}
\hline Treatment & $\begin{array}{l}\text { Day } \\
\text { (post dose) }\end{array}$ & Animal & $\begin{array}{l}\text { Aluminium } \\
\text { concentration } \\
(\mathrm{ng} / \mathrm{ml})\end{array}$ & $\begin{array}{l}\text { Aluminium in } \\
\text { sc. dose site } \\
(\mu \mathrm{g})\end{array}$ & $\begin{array}{l}\text { Percent dose } \\
\text { at sc. dose } \\
\text { site }\end{array}$ & $\begin{array}{l}\text { Mean percent } \\
\text { dose at sc. } \\
\text { dose site }\end{array}$ \\
\hline \multirow{12}{*}{$\begin{array}{l}\text { Aluminium } \\
\text { adjuvant } \\
\text { formulation }\end{array}$} & \multirow[t]{3}{*}{1} & $111 \mathrm{M}$ & 1273 & 52.3 & $35.6 \%$ & \multirow[t]{3}{*}{36.9} \\
\hline & & $112 \mathrm{M}$ & 1745 & 45.1 & $33.4 \%$ & \\
\hline & & $113 \mathrm{M}$ & 2501 & 55.2 & $41.8 \%$ & \\
\hline & \multirow[t]{3}{*}{7} & $131 \mathrm{M}$ & 1380 & 74.9 & $55.5 \%$ & \multirow[t]{3}{*}{78.6} \\
\hline & & $132 \mathrm{M}$ & 1717 & 112 & $76.2 \%$ & \\
\hline & & $133 \mathrm{M}$ & 2150 & 135 & $104 \%$ & \\
\hline & \multirow[t]{3}{*}{14} & $141 \mathrm{M}$ & 1540 & 117 & $83.0 \%$ & \multirow[t]{3}{*}{79.9} \\
\hline & & $142 \mathrm{M}$ & 2000 & 120 & $87.6 \%$ & \\
\hline & & $143 M$ & 1512 & 91.2 & $69.1 \%$ & \\
\hline & \multirow[t]{3}{*}{180} & $181 \mathrm{M}$ & 600 & 56.4 & $40.6 \%$ & \multirow[t]{3}{*}{48.9} \\
\hline & & $182 \mathrm{M}$ & 1020 & 69.5 & $47.3 \%$ & \\
\hline & & $183 \mathrm{M}$ & 967 & 86.9 & $58.7 \%$ & \\
\hline \multirow{3}{*}{$\begin{array}{l}\text { MCT adjuvant } \\
\text { formulation }\end{array}$} & \multirow[t]{3}{*}{1} & $211 \mathrm{M}$ & $<$ LLOQ & ND & ND & \multirow[t]{3}{*}{ ND } \\
\hline & & $212 \mathrm{M}$ & $<$ LLOQ & ND & ND & \\
\hline & & $213 M$ & $<$ LLOQ & ND & ND & \\
\hline \multirow{3}{*}{$\begin{array}{l}\text { Control } \\
\text { formulation }\end{array}$} & \multirow[t]{3}{*}{1} & $301 \mathrm{M}$ & $<$ LLOQ & ND & ND & \multirow[t]{3}{*}{ ND } \\
\hline & & $302 \mathrm{M}$ & $<$ LLOQ & ND & ND & \\
\hline & & $303 \mathrm{M}$ & $<$ LLOQ & ND & ND & \\
\hline
\end{tabular}

sites after aluminium adjuvant formulation administration. The lower percent aluminium dose measured on day 1 compared with days 7, 14 and 180 was attributed to the lower mass of the excised biopsy (approximately 7.4 vs $17.5 \mathrm{~g}$ ) and high likelihood, given the difficult challenge this presents, that some of the day 1 dose site may not have been completely excised. Nevertheless, samples were consistently excised yielding reliable and reproducible data that exhibited $49 \%$ retention of the aluminium dose at 180 days after administration (Figure 1) and it was estimated that approximately 62 weeks would be required to eliminate $95 \%$ of the administered aluminium dose (extrapolated from day 14 and day 180 data).

Considering that the typical lifespan of male Han Wistar rats is between 108 and 112 weeks, the persistence of aluminium remaining at the sc. dose site at 180 days ( 26 weeks) after administration and extrapolated elimination to approximately 62 weeks is worthy of further investigation.

Within the vicinity of the sc. injection site, the biologically available (i.e soluble) forms of aluminium will consist of aluminate $\left(\mathrm{Al}(\mathrm{OH})^{4-}(\mathrm{aq})\right)$ in equilibrium with $\mathrm{Al}^{3+}$ and its hydrolysis products $[19,20]$. However, the dissolution is thought to be relatively slow because of the kinetic inertia of aluminium and the likely protection of dissolution sites on the aluminium salt by adsorbed and/or occluded allergen [20]. Although this preclinical design differs compared with a typical human immunotherapy, the number of injections the rats received (four in total over 2 weeks) corresponds to 1.5 human years. While a typical immunotherapy is administered over 3 years, an updosing phase is typically undertaken which consists of weekly injections (up to 3 each day). As such, a typical patient will experience a burgeoning concentration of aluminium during updosing and while a small proportion of injected aluminium will be present close to the injection site in a rapidly biologically available form, $\mathrm{Al}^{3+}(\mathrm{aq})$, the majority of injected aluminium will be present as insoluble particulates. Although the injections of alum are relatively higher per injection in the rat model, the interstitial fluid (receiving tissue) should in theory be continuously replenished faster in a rat than in human. This replenishment of the receiving tissue will contain soluble ligands for $\mathrm{Al}^{3+}$ (amino and carboxylic acids, albumin, fibrinogen), as well as anchored ligands [20]. These interactions present a dispart kinetic relationship between rat and human model, whereby the rat metabolic rate and protein turnover is much faster. 
Extrapolation of this data to man, based on the duration observed in the rat [21], would predict that an aluminium-containing adjuvant would be retained at the sc. dose site for up to 37 years. While the authors have discovered no similar work has been published in rat, the dissolution, absorption, distribution and elimination (ADME) of aluminium-containing adjuvants in female rabbits using ${ }^{26} \mathrm{Al}$ and accelerator MS (AMS) has been reported [22]. In that study, intramuscular administration of ${ }^{26}$ Aluminium hydroxide at a dose of approximately $0.34 \mathrm{mg} / \mathrm{kg}$ revealed very low systemic concentrations in blood $(<2 \mathrm{ng} / \mathrm{ml})$ and only $17 \%$ of the dose absorbed from the dose site within 28 days. However, the formulation (total dose received) used there is not comparable to this study.

In humans, although the absorption of aluminium by both enteral and inhalation routes are low, the health implications of aluminium exposure are well documented [23]. In addition, aluminium-containing adjuvants have frequent and widespread use in both vaccination and allergy immunotherapy. While both the European Food Standards Agency (EFSA) [24] and the European Medicines Agency (EMA) [5] have defined an aluminium safety criterion as 'tolerable weekly intake' (TWI) for human oral exposure (1 mg/kg/week by diet), macrophagic myofasciitis [25], granuloma [26], subcutaneous nodules [27,28] and ASIA (Autoimmune/inflammatory Syndrome Induced by Adjuvants [29]) have been attributed to the persistence of aluminium after intramuscular administration of aluminium-containing adjuvants. However, evidence in causal relationships with aluminium in this context is pending. The positive benefit/risk assessment of aluminium use in essential prophylactic vaccinations far outweighs any theoretical concerns. However in long-course SCIT, given the complexity and issues in monitoring aluminium accumulation and long latency periods associated with the development of diseases, the repeated administration presents a scenario which warrants further research, consideration and transparency on what is known and not known about its longterm risks in both children and adults, thus paving the way for a more robust risk/benefit assessment and biomonitoring during SCIT trials.

\section{Conclusion \& future perspective}

The presented analysis of aluminium in biological fluids and tissues by ICP-MS, whilst not strictly following the EMEA or US FDA bioanalytical method validation guidance, demonstrates that applying a 'tiered approach' to bioanalysis can offer both the sufficient flexibility and quality to perform scientific investigation. Furthermore, in keeping with a recent European Bioanalytical Forum Workshop on enhancing the Pharma/CRO interface, clear communication, willingness from both parties to be flexible and a shared level of scientific trust is required when such close investigative collaborations are required.

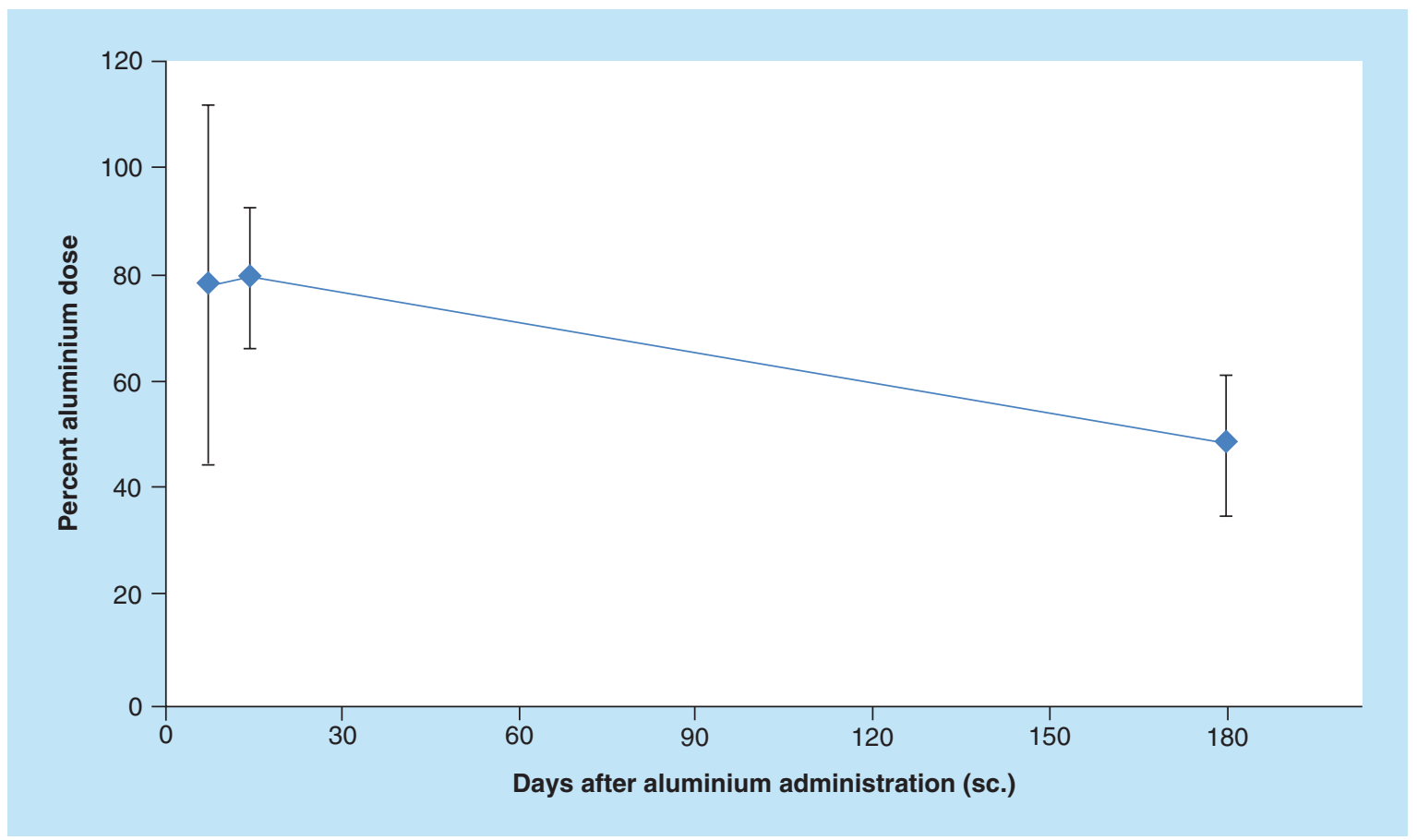

Figure 1. Mean ( \pm standard error of mean) percent aluminium adjuvant dose associated with subcutaneous dose site.

sc.: Subcutaneous. 
Whilst ICP-MS, even the most advanced 3rd generation instruments, cannot compete with AMS for absolute sensitivity, the technique does provide a useful analytical tool for the measurement of elements in biological fluids [30]. Further investigation into the absorption, distribution and elimination of aluminium-containing adjuvants after parenteral administration (at higher doses) by ICP-MS may be warranted. In addition, techniques such as microtome sectioning and laser ablation inductively coupled plasma MS (LA-ICP-MS) may be valuable for bioimaging the aluminium distribution at the sc. dose sites and surrounding tissues [31]. However, for the definitive characterization of the absorption, distribution and elimination of an aluminium-containing adjuvant in rat at a relevant clinical immunotherapy dose, the sensitivity of AMS will be required.

The results described herein provide some further insight into the dissociation and distribution of aluminium hydroxide particulates after subcutaneous administration in the rat. This investigation and confirmation that the aluminium-containing adjuvant was localized at the dose site is somewhat unexpected, especially since well-established biodegradable depots, such as microcrystalline tyrosine, provide a suitable sustained release with far shorter half-life ( $48 \mathrm{~h}$ ) dissolutions at the injection site in a rodent model [32]. It should be noted that until recently the 'depot effect' was considered the classical mechanism of adjuvants. However, the general consensus has shifted and there is indeed no definitive evidence that depot effect significantly contributes to adjuvant activity [33].

While there is insufficient data to fully predict the absorption and elimination of aluminium-containing adjuvants in man, the results of this study are consistent with the likely prolonged retention of aluminium at the dose sites following subcutaneous or intramuscular administration.

Although aluminium is nontoxic under most exposure conditions in man $[2,34]$, it is not an essential ele- ment for biological processes [35], and as such the biological impact of any aluminium exposure is uncertain. Based on the duration and frequency of doses used in clinical subcutaneous immunotherapy, the repeated administration of aluminium-containing adjuvants will likely contribute directly and significantly to an individual's total body burden of aluminium [36-38].

\section{Acknowledgements}

The authors acknowledge P Fernyhough who, as Study Director, was directly responsible for the conduct of the in-life study performed by Covance Laboratories Ltd, Otley Road, Harrogate, North Yorkshire, HG3 1PY, UK.

\section{Financial \& competing interests disclosure}

The research described in this paper was sponsored by Allergy Therapeutics plc, Dominion Way, Worthing, BN14 8SA, UK. MD Heath, MF Kramer and MA Skinner are all employees of Allergy Therapeutics plc. The authors have no other relevant affiliations or financial involvement with any organization or entity with a financial interest in or financial conflict with the subject matter or materials discussed in the manuscript apart from those disclosed.

No writing assistance was utilized in the production of this manuscript.

\section{Ethical conduct of research}

The authors state that they have obtained appropriate institutional review board approval or have followed the principles outlined in the Declaration of Helsinki for all human or animal experimental investigations. In addition, for investigations involving human subjects, informed consent has been obtained from the participants involved.

\section{Open access}

This work is licensed under the Attribution-NonCommercialNoDerivatives 4.0 Unported License. To view a copy of this license, visit http://creativecommons.org/licenses/by-nc$\mathrm{nd} / 4.0 /$

\section{Executive summary}

\section{Background}

- To investigate the absorption, distribution and elimination of aluminium in rat after aluminium adjuvant formulation administration at doses designed to mimic a typical human 3 year subcutaneous immunotherapy (SCIT) dose regimen.

\section{Experimental}

- Inductively coupled plasma MS (ICP-MS) quantification of aluminium in biological fluids and tissues. Assays verified under principles of a 'tiered approach' for purposes of scientific investigation.

Results \& discussion

- No evidence of systemic exposure of aluminium, in brain or in primary organ of elimination (kidney). Extensive and persistent retention of aluminium at the subcutaneous dose sites.

\section{Conclusion}

- Based on the duration and frequency of doses used in clinical subcutaneous immunotherapy, the repeated administration of aluminium-containing adjuvants will likely contribute directly and significantly to an individual's total body burden of aluminium. 


\section{References}

Papers of special note have been highlighted as:

•• of considerable interest

1 Kramer MF, Heath MD. Aluminium in allergen-specific subcutaneous immunotherapy - a German perspective. Vaccine 32, 4140-4148 (2014).

-. Overview of aluminium in subcutaneous immunotherapy.

2 Krewski D et al. Human health risk assessment for aluminium, aluminium oxide, and aluminium hydroxide.

J. Toxicol. Environ. Health B Crit. Rev. 10 (Suppl. 1), 1-269 (2007)

3 US Food and Drug Administration. Code of Federal Regulations; 21CFR610.15 (2015).

www.accessdata.fda.gov

4 European Pharmacopoeia 6.6: Allergen Products $(01 / 2010: 1063)$

http://dgra.de

5 CHMP Safety Working Party's response to the PDCO regarding aluminium hydroxide contained in allergen products. EMA/CHMP/381064/2010 (2010). www.ema.europa.eu

6 Guidance for Industry Bioanalytical Method Validation U.S Department of Health and Human Services Food and Drug Administration Center for Drug Evaluation and Research (CDER) Center for Veterinary Medicine (CVM) (2001). www.fda.gov

7 EMEA/CHMP/EWP/192217/2009, Guideline on bioanalytical method validation.

www.ema.europa.eu

8 Timmerman P, Kall M, Gordon B et al. Best practices in a tiered approach to metabolite quantification: views and recommendations of the European Bioanalysis Forum. Bioanalysis 2(7), 1185-1194 (2010).

9 Lowes S, Hucker R, Jemal M et al. Tiered approaches to chromatographic bioanalytical method performance evaluation: recommendation for best practices and harmonization from the Global Bioanalysis Consortium Harmonization Team. AAPS J. 17(1), 17-23 (2015).

10 Booth B. When do you need a validated assay? Bioanalysis 3(24), 2729-2730 (2011).

11 Abbott R. Tiered approach: sense and sensibility. Bioanalysis 6(5), 611-616 (2014).

12 Timmerman P, White S, McDougall S et al. Tiered approach into practice: scientific validation for chromatography-based assays in early development - a recommendation from the Uropean Bioanalysis Forum. Bioanalysis 7(18), 2387-2398 (2015).

13 Sagan C. The Demon Haunted World: Science as a Candle in the Dark (1st Edition). Ballantine, NY, USA, 213 (1997).

14 Goullé J-P, Mahieu L, Castermant J et al. Metal and metalloid multi-elementary ICP-MS validation in whole blood, plasma, urine and hair: reference values. Forensic Sci. Int. 153, 39-44 (2005).

15 Goullé J-P, Saussereau E, Mahieu L, Guerbert M. Current role of ICP-MS in clinical toxicology and forensic toxicology: a metallic profile. Bioanalysis 6(17), 2245-2259 (2014).
16 Exley C, Burgess E, Day J, Jeffery E, Yokel A. Aluminium toxicokinetics. J. Toxicol. Environ. Health 48(6), 569-584 (1996).

17 Lindblad E. Aluminium compounds for use in vaccines. Immunol. Cell Biol. 82, 497-505 (2004).

18 Ghimire T. The mechanisms of action of vaccines containing aluminium adjuvants: an in vitro vs in vivo paradigm. SpringerPlus 4(181), 1-18 (2015).

19 Martin B. The chemistry of aluminium as related to biology and medicine. Clin. Chem. 32(10), 1797-1806 (1986).

20 Exley C, Siesjo P, Eriksson H. The immunobiology of aluminium adjuvants: how do they really work? Trends Immunol. 31(3), 103-109 (2010)

21 Sengupta P. The laboratory rat: relating its age with human's. Int. J. Prevent. Med. 4(6), 624-630 (2012).

22 Flarend $\mathrm{R}, \mathrm{Hem} \mathrm{S}$, White $\mathrm{J}$ et al. In vivo absorption of aluminium containing vaccine adjuvants using ${ }^{26} \mathrm{Al}$. Vaccine 15(12), 1314-1318 (1997).

-. Comparable AMS determination of aluminium ADME in rabbits.

23 Sjögren B, Irgren A, Montelius J, Yokel R. Aluminium. In: Handbook on the Toxicology of Metals(4th Edition). Nordberg G, Fowler B and Nordberg M (Eds). Academic Press, London, UK 549-564 (2015).

24 Safety of aluminium from dietary intake. Scientific opinion of the panel on food additives, flavourings, processing aids and materials in contact with food. Eur. Food Saf. Authority J. 754, $1-24$ (2008).

25 Gherardi R, Coquet M, Cherin P et al. Macrophagic myofasciitis lesions assess long-term persistence of vaccinederived aluminium hydroxide in muscle. Brain (124), 1821-1831 (2001).

26 Vogelbruch M, Nuss B, Körner M, Kapp A, Kiehl P. Aluminium-induced granulomas after inaccurate intradermal hyposensitization injections of aluminium-adsorbed depot preparations. Allergy 55, 883-887 (2000).

27 Avcin S, Jazbec J, Jancar J. Subcuaneous nodule after vaccination with an aluminium-containing vaccine. Acta Dermatovenerol. Alp. Pannonica Adriat. 17(4), 182-184 (2008).

28 Chong H, Brady K, Metze D, Calonje E. Persistent nodules at injection sites (aluminium granuloma - clinicopathological study of 14 cases with a diverse range of histological reaction patterns. Histopathology 48, 182-188 (2005).

29 Perricone C, Colafrancesco S, Mazor R, Soriano A, AgmonLevin N, Shoenfeld Y. Autoimmune/inflammatory syndrome induced by adjuvants (ASIA) 2013: Unveiling the pathogenic, clinical and diagnostic aspects. J. Autoimmun. 47, 1-16 (2013).

Tudan, C, Weber, F, Levine K. The status of trace element analysis in biological systems. Bioanalysis 3(15), 1695-1697 (2011).

31 Lockyer N. Bioimaging of elements and small molecules using MS. Bioanalysis 3(10), 1047-1051 (2011).

32 Wheeler AW, Moran DM, Robins BE, Driscoll A. L-tyrosine as an immunological adjuvant. Int. Arch. Allergy Appl. Immunol. 69, 113-119 (1982). 
33 Marrack P, McKee AS, Munks MW. Towards an understanding of the adjuvant action of aluminium. Nat. Rev. Immunol. 9(4), 287-293 (2009).

34 Aluminium in drinking water. Background document for development of WHO Guidelines for drinking-water quality. World Health Organisation WHO/HSE/WSH/10.01/13. www.who.int

35 Exley C. Darwin, natural selection and the biological essentiality of aluminium and silicon. Trends Biochem. Sci. 34, 589-593 (2009).
36 Exley C. Human exposure to aluminium. Environ. Sci. Process. Impacts 15, 1807-1816 (2013).

-• Critical assessment of aluminium body burden.

37 Jensen-Jarolim E. Aluminium allergies and allergen immunotherapy. World Allergy Organ. J. 8(7), 1-6 (2015).

-. Review of current concerns with regard to continued use of aluminium adjuvants.

38 Exley C. Aluminium adjuvants and adverse events in subcutaneous allergy immunotherapy. Allergy Asthma Clin. Immunol. 10(4), 1-5 (2014). 